\title{
Golgi Bypass: Skirting Around the Heart of Classical Secretion
}

\author{
Adam G. Grieve and Catherine Rabouille \\ Cell Microscopy Centre, Department of Cell Biology, University Medical Center Utrecht, \\ Heidelberglaan 100, Utrecht, The Netherlands* \\ Correspondence: c.rabouille@hubrecht.eu
}

Classical secretion consists of the delivery of transmembrane and soluble proteins to the plasma membrane and the extracellular medium, respectively, and is mediated by the organelles of the secretory pathway, the Endoplasmic Reticulum (ER), the ER exit sites, and the Golgi, as described by the Nobel Prize winner George Palade (Palade 1975). At the center of this transport route, the Golgi stack has a major role in modifying, processing, sorting, and dispatching newly synthesized proteins to their final destinations. More recently, however, it has become clear that an increasing number of transmembrane proteins reach the plasma membrane unconventionally, either by exiting the ER in non-COPII vesicles or by bypassing the Golgi. Here, we discuss the evidence for Golgi bypass and the possible physiological benefits of it. Intriguingly, at least during Drosophila development, Golgi bypass seems to be mediated by a Golgi protein, dGRASP, which is found ectopically localized to the plasma membrane.

$T^{\text {he }}$ he secretion of signal peptide-containing and transmembrane proteins through the cellular organelles that form the secretory pathway has been very well characterized over the years (Rothman 1994; Lee et al. 2004). During their translation, signal peptide-containing proteins are specifically recognized in the cytoplasm by the signal recognition particle and localize to the ER by virtue of the SRP binding its receptor (Nagai et al. 2003; Osborne et al. 2005). Other transmembrane proteins are embedded in the ER membrane by a

*Present address of both authors: Hubrecht Institute for Developmental Biology and Stem Cell Research, Uppsalalaan 8, Utrecht, The Netherlands posttranslational mechanism called C-tail anchoring by the GET complex (Schuldiner et al. 2008). Following transfer into or across the ER membrane, nascent proteins undergo folding, oligomerization, and addition of oligosaccharide chains followed by exit via specialized landmarks, known as ER exit sites (ERES) in mammalian cells and transitional ER (tER) sites in yeast and Drosophila. Both sites are characterized by the presence of cargo-containing coat protein complex II (COPII)-coated vesicles (Bonifacino and Glick 2004; Lee et al. 2004). Thereafter, most proteins are transported through the Golgi (in a manner that is still very much debated) before reaching their final destination, such as the plasma membrane for

Editors: Graham Warren and James Rothman

Additional Perspectives on The Golgi available at www.cshperspectives.org

Copyright (C) 2011 Cold Spring Harbor Laboratory Press; all rights reserved; doi: 10.1101/cshperspect.a005298

Cite this article as Cold Spring Harb Perspect Biol 2011;3:a005298 


\section{A.G. Grieve and C. Rabouille}

many transmembrane proteins and the extracellular medium for secreted proteins (Mellman and Warren 2000) (Fig. 1, red arrows).

More recently, however, several examples of protein trafficking that deviate from this dogma have been discovered. First, an increasing number of cytoplasmic proteins (such as IL-1 $\beta$, FGF2, MIF, and AcbA/Acb1) that do not harbor a signal peptide are found in the extracellular medium, and these display a wide range of

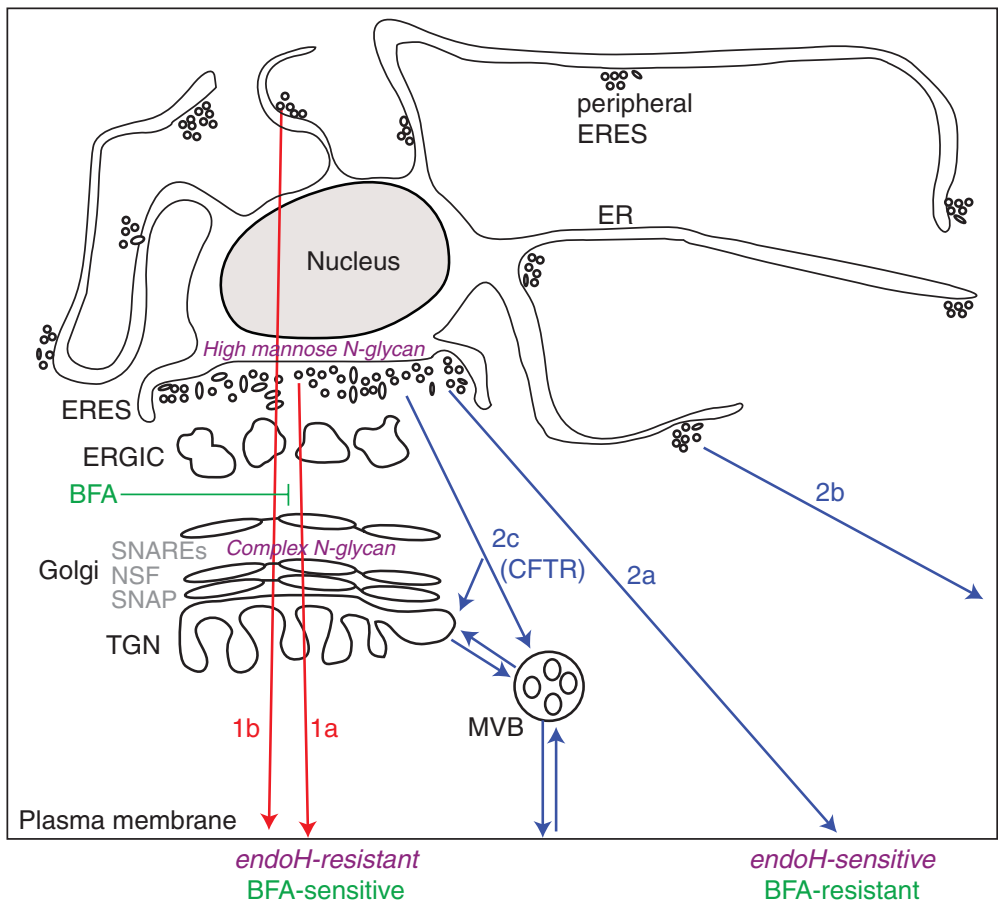

Figure 1. Classical trafficking, from the ER to the Golgi to the plasma membrane, is represented by the red arrows. A cargo protein can exit from an ERES in close proximity to the cis-Golgi (route 1a) or a peripheral ERES (route 1b), but irrespective of its ER exit, this protein follows a distinct pathway through the Golgi to the plasma membrane. This pathway is dependent on known SNARE proteins, NSF and SNAPs. As proteins pass from the ER and through the Golgi, their ER-derived high mannose oligosaccharides are modified by addition of complex sugars rendering these proteins EndoH-resistant. BFA treatment or loss of function of intraGolgi SNAREs would lead to the retention of these proteins in the ER or Golgi and their diminished presence at the plasma membrane.

Potential routes for Golgi bypass are represented by blue arrows. Like classical cargo proteins, Golgi bypass cargoes may exit from an ERES near the cis-Golgi (routes 2a,c) or a peripheral ERES (route 2b). However, the immediate fate of these proteins deviates from the classical pathway. A protein following route $2 \mathrm{a}$ (from an ERES near the cis-Golgi) or $2 \mathrm{~b}$ (from a peripheral ERES) would traffic on ER-derived transport intermediates directly to the plasma membrane, routes perhaps taken by CD45 or $\alpha$ PS1. This route would require a specific set of SNAREs, yet to be identified. As these proteins do not pass through the Golgi stack, their high mannose $N$ glycans remain sensitive to EndoH. These pathways are also revealed by blocking passage through the Golgi either by the application of BFA, or by the loss of function of intra-Golgi SNAREs, (e.g., Syntaxin 5), and observing their continued transport to the plasma membrane. Proteins that follow route $2 \mathrm{c}$ would bypass the Golgi stack via an endosomal intermediate, which would facilitate their delivery to the plasma membrane via conventional endosomal fusion machinery. In the case of CFTR, its exit from the ER may occur from either ERES location to the TGN or endosomes. If it is directly delivered to endosomes, it is likely recycled back to the TGN in which the observed oligosaccharide modifications take place before reaching the plasma membrane. 
critical activities. This "cytoplasmic protein unconventional secretion" has been extensively discussed elsewhere (Nickel and Seedorf 2008; Nickel and Rabouille 2009) and will not be covered in this volume, except for a brief note toward the end. Second, a small subset of proteins does not exit the ER by virtue of classical COPII-coated vesicles. Third, a few transmembrane proteins have been shown to reach the plasma membrane, bypassing the Golgi, which is the focus of this article.

Why some proteins follow an unconventional route of secretion is intriguing but on the whole largely unknown. Through evolution, the cell has segregated processes within membrane compartments to maintain and optimize cellular functions. Why would mechanisms evolve to traffic a subset of proteins via unconventional routes? In this article, we discuss examples of Golgi bypass as well as outline why and how some proteins escape the conventional secretory pathway.

\section{ATYPICAL ER EXIT VIA COPII-INDEPENDENT VESICLES}

ER exit represents the first stage at which a transmembrane protein can deviate from the classical secretion route. Proteins destined for the plasma membrane exit via ERES and traffic to the ER-Golgi Intermediate Compartment (ERGIC) via COPII-coated vesicles. This process has been very well characterized. The large multidomain protein Sec16 is thought to provide a platform for ERES formation, which in combination with the Sec12 GEF leads to the activation and concentration of the Sarl GTPase (Watson et al. 2006; Ivan et al. 2008; Hughes et al. 2009). The membrane recruitment of Sar1 initiates the sequential assembly of two coat heterodimers, Sec23-Sec24 and Sec13-Sec31, to complete the COPII coat (Gurkan et al. 2006; Stagg et al. 2006; Budnik and Stephens 2009). Recruitment of the COPII subunits, which are conserved in all eukaryotes, not only builds the coat structure, but also serves as a sorting device either directly or through a receptor for cargo selection (Stagg et al. 2008).
Hsp150, a soluble yeast glycoprotein, is an exception to this process. It contains an aminoterminal signal peptide and should, therefore, traffic conventionally to the plasma membrane. Its surface localization, however, is independent of the key COPII-coat components Sec13 and Sec24 (Fatal et al. 2004). Furthermore, ER exit of Hsp150-positive vesicles occurs at specific tER sites that do not contain Sec24. Whether Hsp150 also bypasses the Golgi is not yet clear and warrants further investigation.

A similar non-COPII mediated exit has been reported for the voltage-sensitive potassium channels, $\mathrm{Kv} 4 \mathrm{~K}^{+}$. When associated with their interacting proteins, KChIPs, $\mathrm{Kv} 4 \mathrm{~K}^{+}$channel trafficking is unaffected by overexpression of dominant-negative Sar1 (Hasdemir et al. 2005), which is known to block COPII-mediated ER exit (Aridor et al. 1995; Rowe et al. 1996).

Last, the ER exit of EDEM1 (ER degradationenhancing mannosidase-like 1) and OS-9 (an ER lectin) also provide an exciting example of cargo bypassing the COPII machinery. EDEM1 and OS-9 are key regulators of ER-associated degradation (ERAD) and target terminally misfolded glycoproteins in the ER for degradation by removing their mannose groups, thus accelerating their recognition by the ERAD machinery (Olivari et al. 2006; Christianson et al. 2008). To attenuate the ERAD activity in the ER under normal situations, EDEM1 and OS-9 are prevented from accumulating in this organelle and are rapidly delivered to late endosomes/ lysosomes where they are turned over (Cali et al. 2008). Strikingly, their ER exit is mediated by a mechanism that seems to be COPII-independent (Zuber et al. 2007; Cali et al. 2008), and occurs at sites in the rough ER, distinct from typical ERES. This suggests that ER exit of these two proteins, like Hsp150, is spatially segregated along ER cisternae (Zuber et al. 2007; Cali et al. 2008). EDEM1 exit from the ER involves the protein LC3-I but not LC3-II, the lipid bound form of the protein that is a key marker of autophagy (Klionsky et al. 2008), indicating that EDEM1 exit is not mediated by the autophagic process (Reggiori et al. 2010). Furthermore, it is thought that this pool of EDEM1 en route to the endosomal system also bypasses the Golgi. 
A.G. Grieve and C. Rabouille

\section{DETECTING GOLGI BYPASS}

\section{EndoH Sensitivity}

As mentioned in the introduction, following exit from the ER, most newly synthesized proteins reach the Golgi (Watson and Stephens 2005) in which they can be modified, proteolytically processed and dispatched to their final destination, the plasma membrane, the extracellular medium or an organelle of the endolysosomal system (with the exception of the mitochondria and peroxisomes) (Keller and Simons 1997).

One major protein modification that occurs in the Golgi, at least in mammalian cells, is construction of $\mathrm{N}$-linked complex oligosaccharide chains (see Stanley 2011). The majority of proteins that enter the ER are glycosylated with a high mannose-containing, $\mathrm{N}$-linked oligosaccharide core. After reaching the Golgi, oligosaccharide-modifying enzymes trim and add sugars to this core, generating complex $\mathrm{N}$-glycans (Roth 2002) (Fig. 1; route 1a,b). Therefore, a protein that bypasses the Golgi would retain its initial high mannose oligosaccharide core. These changes in glycosylation status can be detected using Endoglycosidase $\mathrm{H}$ (EndoH). ${ }^{1}$ One of the first modifications that occur in the Golgi is the addition an $\mathrm{N}$-acetylglucosamine sugar to the mannose oligosaccharide. The resulting product is no longer a substrate for EndoH (EndoH-resistant) (Medzihradszky 2005). Consequently, proteins that are resistant to EndoH are thought to be conventionally trafficked through the Golgi whereas those that remain sensitive to its activity could, in principle, have bypassed it. Therefore, EndoH sensitivity can be used as a read-out to detect Golgi bypass of proteins, however it does not define the pathway.

\section{Brefeldin A Resistance}

Transport through the early secretory pathway relies on another set of coated vesicular intermediates known as coatamer protein complex

${ }^{1}$ EndoH catalyses the hydrolysis of the diacetylchitobiose core of the oligosaccharide between the two $\mathrm{N}$-acetylglucosamine residues
I (COPI)-coated vesicles (see Lorente-Rodriguez and Barlowe 2011; Wieland 2011). The COPI coat consists of seven proteins that form a multiprotein complex, much like the COPII coat (Lee and Goldberg 2010), which, together with the small GTPase ARF1 decorates vesicular intermediates primarily formed at the Golgi. COPI-coated vesicles mediate retrograde movement of resident Golgi enzymes and proteins that have to be reused within the Golgi and also recycled back for ER exit (such as SNARE proteins and the KDEL receptor) (Pelham and Rothman 2000; Rabouille and Klumperman 2005). The ARF1 GTPase is essential for COPI coat formation (see Wieland 2011) and can be inhibited by Brefeldin A (BFA, see Box 1), a fungal toxin that interferes with recruitment to Golgi membranes and activation of ARF1 (Helms and Rothman 1992). BFA treatment thus blocks retrograde transport from the Golgi resulting in a strong impairment of anterograde trafficking through this organelle, and cargo delivery to post-Golgi compartments of the secretory pathway can be totally blocked. In most cells, BFA treatment also results in the absorption of the Golgi membrane into the ER (LippincottSchwartz et al. 1989). Therefore, it is assumed that a protein reaching the plasma membrane following BFA treatment does not use the conventional ER-Golgi secretory route. However, as discussed in Box 1, the Golgi in some cell types, such as polarized MDCK and PtK1 cells, is not reabsorbed into the ER after treatment with standard doses of BFA (Ktistakis et al. 1991; Chen et al. 1992; Oda et al. 1995). Even in these cells, however, BFA efficiently blocks the majority of conventional anterograde transport to the plasma membrane, albeit at much higher doses.

\section{Golgi SNARE Independence}

The fusion of vesicular intermediates in the secretory pathway is determined by SNAREs (soluble N-ethylmaleimide-sensitive fusion protein (NSF) accessory protein (SNAP) receptors) and SM (Sec1/Munc-18-like) proteins. These serve to specifically bring two membranes into close proximity to drive lipid bilayer fusion 
(see Malsam and Söllner 2011; Sudhof and Rothman 2009). SNAREs can be divided into two classes: target SNAREs (t-SNAREs) and vesicle SNAREs (v-SNAREs), which are present exclusively on apposing heterotypic membranes. One such t-SNARE, Syntaxin 5 (or Sed5 in yeast) is required for transport to and through the Golgi (Dascher et al. 1994; Nichols and Pelham 1998; Rowe et al. 1998). The importance of Syntaxin 5 in classical secretion is emphasized by the observation that its loss in all model organisms blocks classical secretion through the Golgi (Hardwick and Pelham 1992; Amessou et al. 2007; Schotman et al. 2008).

To summarize, combinations of BFA treatment (and the resulting inhibition of ARF GEFS; see Box 1), transport in the absence of Golgi SNAREs and careful monitoring of the glycosylation state of cargo proteins are often used to identify proteins that might bypass the Golgi.

\section{BOX 1. What does Brefeldin A do?}

The fungal toxin Brefeldin A (BFA) acts on a subset of Sec7 domain-containing GTP-exchange factors (GEFs) responsible mainly for the activation of ARF1 GTPase, a protein essential to the formation of COPI coats on donor membranes in the secretory pathway (as discussed in the main text). Treatment with BFA interferes with the GDP-GTP exchange by binding to the initial complex between ARF1, GDP, and the GEFs (such as GBF1, BIG1, and BIG2), thus preventing the exchange and release of activated ARF1-GTP. As a result, the formation (and localization) of COPI coats on Golgi membranes is inhibited.

In most cells (most commonly used being HeLa or COS-7 cells), the loss of COPI coats from Golgi membranes leads to the formation of extensive tubules from the Golgi along microtubule networks (within 5-10 min of BFA application), which do not detach, but are eventually absorbed into the ER (Sciaky et al. 1997). BFA treatment essentially leads to the formation of a hybrid ER-Golgi compartment, which can be described as a morphological phenotype. As a result, the use of BFA causes a block in bulk flow from the ER to and through the Golgi, a functional effect of BFA.

Some cell lines, however, have been reported to be "BFA-resistant" because treatment with this toxin does not cause the morphological phenotype of reabsorption of the Golgi into the ER. The most characterized BFA-resistant cells are MDCK. It has recently been shown that MDCK cells express a point mutant version of the ARF-GEF, GBF1, which makes these cells resistant to BFA (Lanke et al. 2009). Although this remains to be proven, it is possible that the mutation interferes with BFA binding to GBF1. In support of this interpretation, BFA-treated polarized MDCK cells do not lose their COPI coat from the Golgi and a hybrid ER-Golgi compartment does not form. Nevertheless, in polarized MDCK cells, ER to Golgi transport to the apical plasma membrane is inhibited, whereas transport to the basolateral side is unaffected.

However, when MDCKs are grown under conditions that do not sustain polarity (i.e., in a low calcium and low temperature environment), BFA leads to the reabsorption of the Golgi into the ER (exactly as HeLa cells), perhaps suggesting that the GBF1 mutation is thermo-sensitive and calciumsensitive. Furthermore, recent work has shown that treating polarized MDCK cells with 5- to 50-fold higher doses of BFA is sufficient to block bulk apical and basolateral transport through the Golgi (Tveit et al. 2009). This observation suggests that the point mutation in GBF1 may lead to its desensitization to BFA, which can be overcome simply by increasing the drug concentration. Essentially, polarized MDCK cells display a functional sensitivity to BFA treatment that is seemingly uncoupled from the 'known' morphological effect of the drug on the Golgi, at least at low doses. Interestingly, it has been shown that high doses of BFA induce Golgi bypass in MDCK cells (discussed further in the main text). Taken together, although the use of BFA as an inhibitor of ER-Golgi protein trafficking in the secretory pathway has become a common tool, there are differences, sometimes subtle, in its effects dependent on cell type and BFA concentration used. Furthermore, BFA also affects the TGN, endosomes, lysosomes, and plasma membrane, suggesting the existence of additional molecular targets. 
A.G. Grieve and C. Rabouille

A summary of these effects can be seen in the table below:

Table 1. Effects of BFA on different cell types.

\begin{tabular}{|c|c|c|c|c|c|}
\hline Cell type & Concentration & $\begin{array}{l}\text { Collapse of } \\
\text { Golgi into } \\
\text { the ER }\end{array}$ & $\begin{array}{l}\text { Block of ER } \\
\text { to Golgi } \\
\text { transport? }\end{array}$ & Other effects? & References \\
\hline $\begin{array}{l}\text { HeLa } \\
\text { CHO } \\
\text { Cos-7 } \\
\text { NRK } \\
\text { HepG2 } \\
\text { Rat } \\
\text { Hepatocytes }\end{array}$ & $1-10 \mu \mathrm{g} / \mathrm{ml}$ & Yes & Yes & $\begin{array}{l}\text {-Lysosomes form a } \\
\text { microtubule-dependent } \\
\text { network } \\
\text {-Tubulated TGN } \\
\text { connects with endosomes } \\
\text { (mixed TGN/EE) }\end{array}$ & $\begin{array}{l}\text { (Misumi et al. 1986; } \\
\text { Fujiwara et al. 1988; } \\
\text { Doms et al. 1989; } \\
\text { Lippincott-Schwartz } \\
\text { et al. 1989; } \\
\text { Lippincott-Schwartz } \\
\text { et al. 1991; Pelham } \\
\text { 1991; Wood et al. } \\
\text { 1991; Strous et al. } \\
\text { 1993; van Meer and } \\
\text { van 't Hof 1993; } \\
\text { Sciaky et al. 1997) }\end{array}$ \\
\hline PtK1 & $2-5 \mu \mathrm{g} / \mathrm{ml}$ & No & No & $\begin{array}{l}\text { - Tubulated early } \\
\text { endosomes }\end{array}$ & (Ktistakis et al. 1991) \\
\hline MDCK & $1-5 \mu \mathrm{g} / \mathrm{ml}$ & No & $\begin{array}{l}\text {-Yes, } \\
\text { transport to } \\
\text { the apical } \\
\text { membrane } \\
\text {-No, } \\
\text { transport to } \\
\text { the } \\
\text { basolateral } \\
\text { membrane is } \\
\text { unaffected }\end{array}$ & $\begin{array}{l}\text {-Selective inhibition of } \\
\text { transcytosis } \\
\text {-Enhanced TfR } \\
\text { transcytosis } \\
\text {-Tubulated endosomes } \\
\text {-TGN tubulation } \\
\text {-Stimulates apical } \\
\text { transport and slows } \\
\text { basolateral recycling of } \\
\text { TfR } \\
\text {-Increases apical } \\
\text { endocytosis } \\
\text {-Induces Golgi bypass in } \\
\text { the apical direction }\end{array}$ & $\begin{array}{l}\text { (Hunziker et al. 1991; } \\
\text { Lippincott-Schwartz } \\
\text { et al. 1991; Low et al. } \\
\text { 1991; Pelham 1991; } \\
\text { Sandvig et al. 1991; } \\
\text { Prydz et al. 1992; Wan } \\
\text { et al. 1992; Matter } \\
\text { et al. 1993; Wagner } \\
\text { et al. 1994; Futter } \\
\text { et al. 1998; Shitara } \\
\text { et al. 1998; Wang et al. } \\
\text { 2001; Tveit et al. } \\
\text { 2009) }\end{array}$ \\
\hline $\begin{array}{l}\text { Nonpolarized } \\
\text { MDCK }\end{array}$ & $\begin{array}{l}2-5 \mu \mathrm{g} / \mathrm{ml} \text {, } \\
\text { low calcium } \\
\text { and low } \\
\text { temperature }\end{array}$ & Yes & Not tested & & (Burdett 2002) \\
\hline $\begin{array}{l}\text { Polarized } \\
\text { MDCK }\end{array}$ & $50 \mu \mathrm{g} / \mathrm{ml}$ & $\begin{array}{l}\text { Not } \\
\text { tested }\end{array}$ & $\begin{array}{l}\text { Yes, to apical } \\
\text { and } \\
\text { basolateral } \\
\text { membranes }\end{array}$ & $\begin{array}{l}\text { Induces Golgi bypass in } \\
\text { apical and basolateral } \\
\text { directions }\end{array}$ & (Tveit et al. 2009) \\
\hline Caco-2 & $1-5 \mu \mathrm{g} / \mathrm{ml}$ & Yes & Yes & $\begin{array}{l}\text {-Enhanced TfR } \\
\text { transcytosis }\end{array}$ & $\begin{array}{l}\text { (van Meer and van 't } \\
\text { Hof 1993; Shah and } \\
\text { Shen 1994; Bose et al. } \\
\text { 1998) }\end{array}$ \\
\hline $\begin{array}{l}\text { Drosophila S2 } \\
\text { cells }\end{array}$ & $15-30 \mu \mathrm{g} / \mathrm{ml}$ & No & Yes & Clumping of the Golgi & $\begin{array}{l}\text { (Xu et al. 2002a; Xu } \\
\text { et al. 2002b; Kondylis } \\
\text { and Rabouille 2003; } \\
\text { Kondylis et al. 2007) }\end{array}$ \\
\hline
\end{tabular}




\section{KNOWN CARGO BYPASSING THE GOLGI}

To date, a small but significant cohort of transmembrane proteins able to traffic to their desired cellular sites in a BFA-resistant manner has been identified, suggesting that their transport does not require passage through the Golgi (Fig. 1; route 2a,b). Below, we describe evidence for a few of these examples.

\section{CD45}

A pool of CD45, a protein tyrosine phosphatase essential for T-cell and thymocyte development, has been shown to appear at the plasma membrane in a BFA-insensitive manner (Baldwin and Ostergaard 2002). In untreated $T$ cells, CD45 reaches the plasma membrane in two differentially glycosylated forms, one EndoHresistant (classical) and one EndoH-sensitive that potentially bypasses the Golgi. Interestingly, the pool of EndoH-sensitive proteins reaches the plasma membrane approximately three times faster than the EndoH-resistant forms, indicating that at least this Golgi bypass pathway supports faster secretion than the classical route. Furthermore, EndoH-sensitive CD45 appears on the cell surface under normal growth conditions, suggesting that Golgi bypass of CD45 might also be a constitutive process. Surprisingly, no tests have been made to assess whether the high mannose form of CD45 retains full phosphatase activity or the same substrate specificity. If the enzymatic activity of CD45 is altered, Golgi bypass could represent an interesting means by which to regulate CD45 activity.

\section{Hemichannel Proteins}

The transmembrane proteins of the connexin family form gap junctions. These are membrane channels connecting the cytoplasm of neighboring cells to allow the passage of solutes, ions, and signaling molecules (Kumar and Gilula 1996; Saez et al. 2003). Each connexin-mediated gap junction comprises two hemichannels each contributed by a neighboring cell, which are formed by six homo- or hetero-connexin dimers. Interestingly, some connexins (e.g., Connexin 26 and 30) are able to traffic in a BFA-resistant manner, whereas others, such as Connexin 32 and 43 seem to be wholly conventional in their transport to the plasma membrane (Martin et al. 2001; Qu et al. 2009).

Although similar to connexins structurally (presence of 4 transmembrane segments and formation of membrane channels), pannexins have been shown to be evolutionarily distinct and are more homologous to innexins, the sole gap junction proteins that exist in invertebrates, (Baranova et al. 2004). Both innexins and pannexins form single intramembrane channels that communicate with the extracellular environment by allowing the passage of molecules and ions such as ATP and calcium ions, respectively (Bauer et al.2005; D'Hondt et al.2009). Like connexins, pannexins and innexins also homo- and hetero-oligomerize, and some of the subunits such as pannexin 1 and 3, are able to traffic both conventionally as well as reach the plasma membrane during BFA treatment, suggesting an interesting interplay between classical secretion and Golgi bypass (Penuela et al. 2007). Each of the human pannexins 1, 2, and 3 is uniquely glycosylated with a single oligosaccharide chain and their glycosylation status has been shown to regulate the mixing of the different subunits (Penuela et al. 2009). This observation provides an attractive possibility that Golgi bypass could regulate pannexin intermixing.

\section{Drosophila $\alpha$ PS1 Integrin}

Golgi bypass has also been observed in Drosophila follicular epithelial cells (Schotman et al. 2008; Schotman et al. 2009). During a key stage termed 10B in the development and growth of the egg chamber during oogenesis, the columnar epithelial cells that surround the oocyte are required to flatten to maintain their coverage. During this flattening process, new plasma membrane contacts with the extracellular matrix (ECM) are made by converting the basolateral membrane into basal contacts. The basal contacts with the ECM are generated by the use of adhesive proteins such as $\alpha$ PS1 integrin, the secretion of which sharply increases at this stage of Drosophila development. Surprisingly, this $\alpha$ PS1 secretion bypasses the Golgi because the 
transport of this integrin is BFA-insensitive and Syntaxin 5 independent. Before Stage 10B, interestingly, $\alpha$ PS1 secretion occurs conventionally, in a BFA-sensitive, Syntaxin-5-dependent manner.

\section{CFTR}

The most documented example of a cargo bypassing the Golgi stack is the cystic fibrosis transmembrane conductance regulator (CFTR), the protein mutated in the genetic disease cystic fibrosis (Tsui 1992; Welsh and Smith 1993). CFTR exit from the ER is dependent on COPIIcoat components in all cell types (Wang et al. 2004). Astonishingly, in a cell-type specific manner and despite canonical ER exit, maturation of CFTR N-glycans into complex oligosaccharides is insensitive to the loss of ARF1, Syntaxin 5, and Rab1A/Rab2 GTPases, proteins required for transport from the ER to the Golgi (Yoo et al. 2002). Interestingly, CFTR transport through this unconventional route is blocked by overexpression of dominant negative Syntaxin 13, a t-SNARE that resides at the TGN/endosomal system. This result confirms the potential existence of a secretion route for CFTR from the ER to the plasma membrane passing through the TGN or endosomes, then on to the plasma membrane (Yoo et al. 2002) (Fig. 1; route 2c). As the N-glycans of CFTR are modified, it suggests that if CFTR reaches endosomes directly, it must be recycled to the Golgi prior to plasma membrane delivery.

Recently, the Golgi bypass of CFTR en route to the plasma membrane has implicated a pericentriolar intermediate compartment (pIC), positive for the small ER to Golgi GTPase Rabla (Tisdale et al. 1992; Nuoffer et al. 1994), stably associated with the centrosome and with direct connections with the endosomal system (Sannerud et al. 2006; Marie et al. 2009). Through the use of temperature shifts, a common method to block protein traffic in different compartments of the secretory pathway, CFTR has been shown to accumulate in the pIC. Following release of this block, CFTR is rapidly transported to the plasma membrane. Importantly, the morphology of the pIC and its association with recycling endosomes are resistant to BFA treatment. However, in these cells, BFA blocked CFTR in the ER, but following washout of the drug, CFTR arrived rapidly at the pIC and the plasma membrane preceding Golgi reformation.

\section{Induction of Golgi Bypass by BFA}

Evidence has been gathered that Golgi bypass could be triggered not only during development, as described above for $\alpha$ PS1 integrins, but also pharmacologically, for instance following BFA treatment.

A small pool of the EndoH-sensitive proteoglycan Serglycin has been shown to arrive at the plasma membrane of polarized MDCK cells (Tveit et al. 2009). This pool, however, increases following BFA treatment. At low BFA concentration, EndoH-sensitive Serglycin reaches apical plasma membranes and at higher BFA concentrations, it is also delivered to basolateral membranes (see Box 1 for details). Under these conditions, Serglycin seems to be retained within the Golgi, leading to the hypothesis that cargo accumulation in this organelle may induce its bypass. This was tested further by artificially increasing the steady state level of Serglycin in the Golgi. Addition of KDEL to Serglycin (thus increasing its residency time in the early secretory pathway) in the absence of BFA also induced the delivery of an EndoH-sensitive pool to the apical plasma membrane (thus phenocopying BFA treatment). However, the effect of Serglycin-KDEL on the general secretory competence of the Golgi and the conventional traffic of other proteins was untested. Further work is needed to investigate whether cargo load in the Golgi influences the traffic mode.

\section{WHY BYPASS THE GOLGI?}

The cargoes that so far have been shown to bypass the Golgi are proteins of diverse functions, from channels to enzymes, to junction and adhesive proteins. Although the purpose of Golgi bypass is not well understood, potential reasons why a protein might traffic in this way can be identified. 


\section{Protection of Classical Cargo Proteins}

Golgi bypass could be seen as a preventive measure that the cell employs to avoid deleterious effects on its secreted cargo. For instance, EDEM1 (the ER degradation-enhancing mannosidase-like 1, mentioned above) is thought to be delivered from the ER directly to endosomes/lysosomes without passing through the Golgi (Fatal et al. 2004; Zuber et al. 2007). One reason might be to ensure that EDEM1 mannosidase activity is diverted away from the main secretory route in which a multitude of glycosylated proteins reside or pass through, to possibly avoid the alteration of their oligosaccharides (Hosokawa et al. 2010).

\section{Speed}

Golgi bypass might also appear to be a faster process than classical trafficking through the Golgi, as observed with CD45 (Baldwin and Ostergaard 2002). Except for cells in which rapid secretion occurs (for instance, those of the [neuro] endocrine systems in which secretory vesicles are stored just beneath the plasma membrane ready to release following triggering), this enhanced speed of secretion may represent an efficient/fast way for the cell to up-regulate cell surface expression of a protein in response to extracellular stimuli. This might also be a way for highly polarized cells, such as neurons, to deposit membrane proteins to their growing tips (perhaps from a pool of localized mRNAs (Mohr and Richter 2003) that could be translated on the surrounding ER (Hanus and Ehlers 2008)), without relying on the secretory apparatus of the cell body (including the Golgi), sometimes located meters away. A pathway similar to this is presented in Figure 1 (route $2 \mathrm{~b}$ ).

\section{Regulation of Protein Activity}

Golgi bypass could also be employed to modulate the activity of proteins. The immature, EndoH-sensitive form of CD45 on T cells could specifically be recognized by mannose binding lectins, which are found, for instance, on the surface of stromal cells (Baldwin and
Ostergaard 2001). Vital to T-cell function is the ability to migrate to sites of cell-to-cell adhesion and of inflammation or injury (in which mannose binding lectins have key roles), both processes required for the activation of key signaling cascades. It is possible that Golgi bypass of CD45 supports specific stronger adhesion events between $\mathrm{T}$ cells and mannose binding lectins.

Alternatively, Golgi bypass may regulate the phosphatase activity and/or specificity of CD45. Although not related to CD45, receptor tyrosine phosphatase $\beta$ (RPTP $\beta)$ activity and signaling is inhibited by glycosylation (Abbott et al. 2008), suggesting that the enzymatic activity of protein phosphatases can be sensitive to glycosylation.

Although the reason why Drosophila $\alpha$ PS1 might bypass the Golgi of follicular epithelial cells is unknown, glycosylation and truncation modifications that occur in the Golgi have been shown to modulate the adhesive properties of integrins (Guo et al. 2003; Chen et al. 2006). As the oocyte expands, the follicular epithelium flattens, necessitating a modulated adhesion event through integrins showing differential biochemical properties. In addition, at approximately the same developmental time-point (stage 10B of oogenesis) that $\alpha$ PS1 is unconventionally secreted, $\alpha$ PS2 starts being expressed and synthesized (Delon and Brown 2009). It is known that $\alpha$ integrin subunits are chaperoned by the $\beta$ subunits and they leave the ER as a dimer. It is therefore conceivable that $\alpha$ PS1 takes an alternative secretory route (together with a yet unknown chaperone) to allow the formation of the $\alpha$ PS $2 / \beta P S$ dimer, which is thus then conventionally deposited on the surface as a functional complex after stage $10 \mathrm{~B}$.

\section{Ensuring Correct Function of the Golgi}

The major function of CFTR is to transport chloride ions across membranes (Akabas 2000) and this seems to be crucial for the maintenance of the $\mathrm{pH}$ gradient across Golgi membranes. This, in turn, plays a key role in the modification and secretion of proteins. Therefore, the 
presence of chloride in the cytoplasm, and the function of chloride channels as well as of lysosomal/vacuolar ATPases are critical for the maintenance of the Golgi intra-luminal $\mathrm{pH}$ and in turn of its functional integrity (Edwards and Kahl 2010). In this regard, one likely possibility is that CFTR is routed away from the early Golgi to maintain its $\mathrm{pH}$ gradient and secretory competence. Whether CFTR displays differential activity or is more functional in the Golgi rather than the ER is unknown.

Connexins and pannexins also form channels through the plasma membrane of mammalian cells, which allow passage of small molecules and ions (Kumar and Gilula 1996; Saez et al. 2003). Although the site at which different connexin and pannexin monomers multimerize and become functional is much debated and is often dependent on the subtype (for example, there is evidence of oligomerization of connexins in the ER, ERGIC, and TGN (Koval 2006)), the Golgi bypass of a number of subunits could help prevent the formation of gap junction channels in the Golgi, a process that could also prove to be detrimental to the function of the organelle.

\section{BYPASSING THE GOLGI: HOW? A ROLE FOR GRASP}

The molecular mechanism sustaining conventional secretion is exquisitely complex and tightly regulated. How might the Golgi bypass pathway overcome this rigid regulation? Perhaps the ERES used for this alternative trafficking segregates cargo bypassing the Golgi away from classical anterograde transport. COPII vesicles carrying Golgi bypass cargo might contain a different set of SNAREs thus allowing their direct fusion with the plasma membrane (i.e., Fig. 1; route 2a). Therefore, Golgi bypass is likely to rely on unknown combinations of SNAREs or on specific molecules that are yet to be identified.

However, what is known about Golgi bypass suggests that it uses molecules originally identified for their role in classical trafficking, but in an unusual way. For instance, the ER exit of EDEM1 depends on LC3, a key component and marker of autophagy (Klionsky et al. 2008). However, EDEM1 exit depends on a nonlipidated form of LC3, which is thought to have no direct role in autophagy itself (Reggiori et al. 2010).

Recently, in the process of understanding the mechanism of $\alpha$ PS1 unconventional transport in Drosophila (see "Known Cargo Bypassing the Golgi"), the protein dGRASP was found to be a critical component of this alternative pathway. dGRASP is the single Drosophila homolog of mammalian GRASP55 and GRASP65. To date, these two proteins have been localized only to the Golgi and they play a role in Golgi organization, as stacking factors (Barr et al. 1997; Shorter et al. 1999; Xiang and Wang 2010), and mediators of Golgi ribbon formation (Puthenveedu et al. 2006; reviewed in Ramirez and Lowe 2009; Vinke et al. 2011). Surprisingly, at the stage of $\alpha$ PS1 unconventional deposition to the basal membrane, dGRASP was also found anchored at the same membrane. Furthermore, the transport of $\alpha \mathrm{PS} 1$ integrin was strictly dependent on dGRASP, as, in a null allele of dgrasp it was retained intracellularly, whereas the classical anterograde transport of other transmembrane proteins through the Golgi complex remained unaltered (Schotman et al. 2008). Interestingly, the ectopic localization of dGRASP is not because of a repositioning of the Golgi or to its trafficking from the Golgi to the plasma membrane, but to a specific translation of its targeted mRNA and its subsequent local anchoring to the plasma membrane. The up-regulation and localization of dgrasp mRNA is triggered by developmental events such as mechanical pressure generated on the epithelium by the increasing size of the oocyte that augments epithelial tension (Schotman et al. 2009).

Interestingly, other mRNAs encoding proteins involved in the vesicular transport in the early compartments of the secretory pathway such as Sec16, Rab6, NSF1, SNAP, and Gos28 have been shown to localize to the same plasma membrane domains as dgrasp transcripts. Because these potential translation products are components of the early compartments of the secretory pathway, it has been proposed that 
their localization to the plasma membrane at key developmental stages would allow the tethering of the ER-derived carriers to the cell periphery

Strikingly, in both Dictyostelium and yeast, GRASP has also been shown to be involved in the unconventional secretion of the cytoplasmic protein AcbA/Acb1 (Kinseth et al. 2007; Duran et al. 2010; Manjithaya et al. 2010). If GRASP also plays a role in tethering membrane intermediates involved in this secretion, then the last steps of unconventional secretion of AcbA/ACb1 and Golgi bypass of transmembrane proteins may bear similarities (Nickel and Rabouille 2009).

\section{CONCLUDING REMARKS AND PERSPECTIVES}

Many questions remain regarding Golgi bypass and more direct evidence of its existence is required. The core molecular components that regulate this pathway are largely unknown with the exceptions of Syntaxin 13 and dGRASP. It remains to be seen whether these proteins work within the same pathway, or whether they act within separate Golgi bypass routes. Testing the requirement of each of these proteins in the trafficking of cargoes such as CD45, CFTR, and $\alpha$ PS1 in their respective systems would aid our understanding of Golgi bypass. Furthermore, how these proteins might function to regulate Golgi bypass is largely unknown.

A major unanswered question is whether the GRASP-mediated Golgi bypass pathway observed in Drosophila operates in other epithelia and/or species and what other cargoes it may traffic. In Drosophila follicular epithelial cells, this pathway is under strong developmental control. It is possible that the GRASP-mediated Golgi bypass pathway has been missed previously because this developmental control element is missing in tissue culture environments commonly used for trafficking studies. If this were true, then developing methods that allow this pathway to be revealed in mammalian tissue culture would help in unraveling the molecular requirements, cargoes, and mechanisms of Golgi bypass. Furthermore, live-cell imaging of a protein taking a direct route from the ER to the plasma membrane is still elusive. With a greater understanding of the machinery that drives Golgi bypass, we may one day observe a protein "skirting around the Golgi" in real time.

\section{ACKNOWLEDGMENTS}

We thank our colleagues of the Department of Cell Biology (UMC Utrecht) and our collaborators of the consortium UPS of the ESF EUROCORES EuroMEMBRANE, for helpful discussions, and Fulvio Reggiori for critically reading the manuscript. AG is supported by ESF EuroMEMBRANE programme managed by NWO CW 700.58.702.

\section{REFERENCES}

Abbott KL, Matthews RT, Pierce M. 2008. Receptor tyrosine phosphatase $\beta$ (RPTP $\beta)$ activity and signaling are attenuated by glycosylation and subsequent cell surface galectin-1 binding. J Biol Chem 283: 3302633035.

Akabas MH. 2000. Cystic fibrosis transmembrane conductance regulator. Structure and function of an epithelial chloride channel. J Biol Chem 275: 3729-3732.

Amessou M, Fradagrada A, Falguieres T, Lord JM, Smith DC, Roberts LM, Lamaze C, Johannes L. 2007. Syntaxin 16 and syntaxin 5 are required for efficient retrograde transport of several exogenous and endogenous cargo proteins. J Cell Sci 120: 1457-1468.

Aridor M, Bannykh SI, Rowe T, Balch WE. 1995. Sequential coupling between COPII and COPI vesicle coats in endoplasmic reticulum to Golgi transport. J Cell Biol 131: 875-893.

Baldwin TA, Ostergaard HL. 2001. Developmentally regulated changes in glucosidase II association with, and carbohydrate content of, the protein tyrosine phosphatase CD45. J Immunol 167: 3829-3835.

Baldwin TA, Ostergaard HL. 2002. The protein-tyrosine phosphatase CD45 reaches the cell surface via golgidependent and -independent pathways. J Biol Chem 277: 50333-50340.

Baranova A, Ivanov D, Petrash N, Pestova A, Skoblov M, Kelmanson I, Shagin D, Nazarenko S, Geraymovych E, Litvin O, et al. 2004. The mammalian pannexin family is homologous to the invertebrate innexin gap junction proteins. Genomics 83: 706-716.

Barr FA, Puype M, Vandekerckhove J, Warren G. 1997. GRASP65, a protein involved in the stacking of Golgi cisternae. Cell 91: 253-262.

Bauer R, Loer B, Ostrowski K, Martini J, Weimbs A, Lechner H, Hoch M. 2005. Intercellular communication: the Drosophila innexin multiprotein family of gap junction proteins. Chem Biol 12: 515-526. 
A.G. Grieve and C. Rabouille

Bonifacino JS, Glick BS. 2004. The mechanisms of vesicle budding and fusion. Cell 116: 153-166.

Bose S, Chapin SJ, Seetharam S, Feix J, Mostov KE, Seetharam B. 1998. Brefeldin A (BFA) inhibits basolateral membrane (BLM) delivery and dimerization of transcobalamin II receptor in human intestinal epithelial Caco-2 cells. BFA effects on BLM cholesterol content. J Biol Chem 273: $16163-16169$.

Budnik A, Stephens DJ. 2009. ER exit sites-localization and control of COPII vesicle formation. FEBS Lett 583: 3796-3803.

Burdett ID. 2002. Effects of Brefeldin A on disassembly of the Golgi body in MDCK cells subjected to a $\mathrm{Ca}^{2+}$ shift at low temperature. Eur J Cell Biol 81: 525-528.

Cali T, Galli C, Olivari S, Molinari M. 2008. Segregation and rapid turnover of EDEM1 by an autophagy-like mechanism modulates standard ERAD and folding activities. Biochem Biophys Res Commun 371: 405-410.

Chen X, Jiang J, Yang J, Chen C, Sun M, Wei Y, Guang X, Gu J. 2006. Down-regulation of the expression of $\beta 1$,4-galactosyltransferase $\mathrm{V}$ promotes integrin $\beta 1$ maturation. Biochem Biophys Res Commun 343: 910-916.

Chen CH, Kuwazuru Y, Yoshida T, Nambiar M, Wu HC. 1992. Isolation and characterization of a brefeldin Aresistant mutant of monkey kidney Vero cells. Exp Cell Res 203: 321-328.

Christianson JC, Shaler TA, Tyler RE, Kopito RR. 2008. OS-9 and GRP94 deliver mutant $\alpha 1$-antitrypsin to the Hrd1SEL1L ubiquitin ligase complex for ERAD. Nat Cell Biol 10: $272-282$.

D'Hondt C, Ponsaerts R, De Smedt H, Bultynck G, Himpens B. 2009. Pannexins, distant relatives of the connexin family with specific cellular functions? Bioessays 31 : 953-974.

Dascher C, Matteson J, Balch WE. 1994. Syntaxin 5 regulates endoplasmic reticulum to Golgi transport. J Biol Chem 269: $29363-29366$.

Delon I, Brown NH. 2009. The integrin adhesion complex changes its composition and function during morphogenesis of an epithelium. J Cell Sci 122: 4363-4374.

Doms RW, Russ G, Yewdell JW. 1989. Brefeldin A redistributes resident and itinerant Golgi proteins to the endoplasmic reticulum. J Cell Biol 109: 61-72.

Duran JM, Anjard C, Stefan C, Loomis WF, Malhotra V. 2010. Unconventional secretion of Acb1 is mediated by autophagosomes. J Cell Biol 188: 527-536.

Edwards JC, Kahl CR. 2010. Chloride channels of intracellular membranes. FEBS Lett 584: 2102-2111.

Fatal N, Karhinen L, Jokitalo E, Makarow M. 2004. Active and specific recruitment of a soluble cargo protein for endoplasmic reticulum exit in the absence of functional COPII component Sec24p. J Cell Sci 117: 16651673.

Fujiwara T, Oda K, Yokota S, Takatsuki A, Ikehara Y. 1988. Brefeldin A causes disassembly of the Golgi complex and accumulation of secretory proteins in the endoplasmic reticulum. J Biol Chem 263: 18545-18552.

Futter CE, Gibson A, Allchin EH, Maxwell S, Ruddock LJ, Odorizzi G, Domingo D, Trowbridge IS, Hopkins CR. 1998. In polarized MDCK cells basolateral vesicles arise from clathrin- $\gamma$-adaptin-coated domains on endosomal tubules. J Cell Biol 141: 611-623.

Guo P, Zhang Y, Zhao JH, Wang LY, Guo HB, Zhang XY, Chen HL. 2003. Regulation on the expression and Nglycosylation of integrins by $\mathrm{N}$-acetylglucosaminyltransferase V. Biochem Biophys Res Commun 310: 619626.

Gurkan C, Stagg SM, Lapointe P, Balch WE. 2006. The COPII cage: Unifying principles of vesicle coat assembly. Nat Rev Mol Cell Biol 7: 727-738.

Hanus C, Ehlers MD. 2008. Secretory outposts for the local processing of membrane cargo in neuronal dendrites. Traffic 9: 1437-1445.

Hardwick KG, Pelham HR. 1992. SED5 encodes a 39-kD integral membrane protein required for vesicular transport between the ER and the Golgi complex. J Cell Biol 119: $513-521$.

Hasdemir B, Fitzgerald DJ, Prior IA, Tepikin AV, Burgoyne RD. 2005. Traffic of $\mathrm{Kv} 4 \mathrm{~K}^{+}$channels mediated by KChIP1 is via a novel post-ER vesicular pathway. J Cell Biol 171: 459-469.

Helms JB, Rothman JE. 1992. Inhibition by brefeldin A of a Golgi membrane enzyme that catalyses exchange of guanine nucleotide bound to ARF. Nature 360: 352-354.

Hosokawa N, Tremblay LO, Sleno B, Kamiya Y, Wada I, Nagata K, Kato K, Herscovics A. 2010. EDEM1 accelerates the trimming of $\alpha 1$,2-linked mannose on the $\mathrm{C}$ branch of N-glycans. Glycobiology 20: 567-575.

Hughes H, Budnik A, Schmidt K, Palmer KJ, Mantell J, Noakes C, Johnson A, Carter DA, Verkade P, Watson P, et al. 2009. Organisation of human ER-exit sites: requirements for the localisation of Sec16 to transitional ER. J Cell Sci 122: 2924-2934.

Hunziker W, Whitney JA, Mellman I. 1991. Selective inhibition of transcytosis by brefeldin A in MDCK cells. Cell 67: 617-627.

Ivan V, de Voer G, Xanthakis D, Spoorendonk KM, Kondylis V, Rabouille C. 2008. Drosophila Sec16 mediates the biogenesis of tER sites upstream of Sarl through an arginine-rich motif. Mol Biol Cell 19: 4352-4365.

Keller P, Simons K. 1997. Post-Golgi biosynthetic trafficking. J Cell Sci 110: 3001-3009.

Kinseth MA, Anjard C, Fuller D, Guizzunti G, Loomis WF, Malhotra V. 2007. The Golgi-associated protein GRASP is required for unconventional protein secretion during development. Cell 130: 524-534.

Klionsky DJ, Abeliovich H, Agostinis P, Agrawal DK, Aliev G, Askew DS, Baba M, Baehrecke EH, Bahr BA, Ballabio A, et al. 2008. Guidelines for the use and interpretation of assays for monitoring autophagy in higher eukaryotes. Autophagy 4: 151-175.

Kondylis V, Rabouille C. 2003. A novel role for dp115 in the organization of tER sites in Drosophila. J Cell Biol 162: 185-198.

Kondylis V, van Nispen tot Pannerden HE, Herpers B, Friggi-Grelin F, Rabouille C. 2007. The golgi comprises a paired stack that is separated at G2 by modulation of the actin cytoskeleton through Abi and Scar/WAVE. Dev Cell 12: 901-915.

Koval M. 2006. Pathways and control of connexin oligomerization. Trends Cell Biol 16: 159-166. 
Ktistakis NT, Roth MG, Bloom GS. 1991. PtK1 cells contain a nondiffusible, dominant factor that makes the Golgi apparatus resistant to brefeldin A. J Cell Biol 113: 1009-1023.

Kumar NM, Gilula NB. 1996. The gap junction communication channel. Cell 84: 381-388.

Lanke KH, van der Schaar HM, Belov GA, Feng Q, Duijsings D, Jackson CL, Ehrenfeld E, van Kuppeveld FJ. 2009. GBF1, a guanine nucleotide exchange factor for Arf, is crucial for coxsackievirus B3 RNA replication. $J$ Virol 83: $11940-11949$

Lee C, Goldberg J. 2010. Structure of coatomer cage proteins and the relationship among COPI, COPII, and clathrin vesicle coats. Cell 142: 123-132.

Lee MC, Miller EA, Goldberg J, Orci L, Schekman R. 2004 Bi-directional protein transport between the ER and Golgi. Annu Rev Cell Dev Biol 20: 87-123.

Lippincott-Schwartz J, Yuan LC, Bonifacino JS, Klausner RD. 1989. Rapid redistribution of Golgi proteins into the ER in cells treated with brefeldin A: Evidence for membrane cycling from Golgi to ER. Cell 56: 801-813.

Lippincott-Schwartz J, Yuan L, Tipper C, Amherdt M, Orci L, Klausner RD. 1991. Brefeldin A’s effects on endosomes, lysosomes, and the TGN suggest a general mechanism for regulating organelle structure and membrane traffic. Cell 67: $601-616$.

Lorente-Rodriguez A, Barlowe C. 2011. Entry and Exit Mechanisms at the cis-Face of the Golgi complex. Cold Spring Harb Perspect Biol doi: 10.1101/cshperspect. a005207.

Low SH, Wong SH, Tang BL, Tan P, Subramaniam VN, Hong W. 1991. Inhibition by brefeldin A of protein secretion from the apical cell surface of Madin-Darby canine kidney cells. J Biol Chem 266: 17729-17732.

Malsam J, Söllner TH. 2011. Organization of SNAREs within the Golgi stack. Cold Spring Harb Perspect Biol doi: 10.1101/cshperspect.a005249.

Manjithaya R, Anjard C, Loomis WF, Subramani S. 2010. Unconventional secretion of Pichia pastoris Acbl is dependent on GRASP protein, peroxisomal functions, and autophagosome formation. J Cell Biol 188: 537-546.

Marie M, Dale HA, Sannerud R, Saraste J. 2009. The function of the intermediate compartment in pre-Golgi trafficking involves its stable connection with the centrosome. Mol Biol Cell 20: 4458-4470.

Martin PE, Blundell G, Ahmad S, Errington RJ, Evans WH. 2001. Multiple pathways in the trafficking and assembly of connexin 26, 32 and 43 into gap junction intercellular communication channels. J Cell Sci 114: 38453855.

Matter K, Whitney JA, Yamamoto EM, Mellman I. 1993. Common signals control low density lipoprotein receptor sorting in endosomes and the Golgi complex of MDCK cells. Cell 74: 1053-1064.

Medzihradszky KF. 2005. Characterization of protein N-glycosylation. Methods Enzymol 405: 116-138.

Mellman I, Warren G. 2000. The road taken: past and future foundations of membrane traffic. Cell 100: 99-112.

Misumi Y, Miki K, Takatsuki A, Tamura G, Ikehara Y. 1986. Novel blockade by brefeldin A of intracellular transport of secretory proteins in cultured rat hepatocytes. $J$ Biol Chem 261: 11398-11403.

Mohr E, Richter D. 2003. Local synthesis of the rat Vasopressin precursor in dendrites of in vitro cultured nerve cells. Brain Res Mol Brain Res 114: 115-122.

Nagai K, Oubridge C, Kuglstatter A, Menichelli E, Isel C, Jovine L. 2003. Structure, function and evolution of the signal recognition particle. EMBO J 22: 3479-3485.

Nichols BJ, Pelham HR. 1998. SNAREs and membrane fusion in the Golgi apparatus. Biochim Biophys Acta 1404: $9-31$.

Nickel W, Rabouille C. 2009. Mechanisms of regulated unconventional protein secretion. Nat Rev Mol Cell Biol 10: $148-155$.

Nickel W, Seedorf M. 2008. Unconventional mechanisms of protein transport to the cell surface of eukaryotic cells. Annu Rev Cell Dev Biol 24: 287-308.

Nuoffer C, Davidson HW, Matteson J, Meinkoth J, Balch WE. 1994. A GDP-bound of rab1 inhibits protein export from the endoplasmic reticulum and transport between Golgi compartments. J Cell Biol 125: 225-237.

Oda T, Chen CH, Wu HC. 1995. Ceramide reverses brefeldin A (BFA) resistance in BFA-resistant cell lines. J Biol Chem 270: 4088-4092.

Olivari S, Cali T, Salo KE, Paganetti P, Ruddock LW, Molinari M. 2006. EDEM1 regulates ER-associated degradation by accelerating de-mannosylation of folding-defective polypeptides and by inhibiting their covalent aggregation. Biochem Biophys Res Commun 349: 1278-1284.

Osborne AR, Rapoport TA, van den Berg B. 2005. Protein translocation by the Sec61/SecY channel. Annu Rev Cell Dev Biol 21: 529-550.

Palade G. 1975. Intracellular aspects of the process of protein synthesis. Science 189: 867.

Pelham HR. 1991. Multiple targets for brefeldin A. Cell 67: 449-451.

Pelham HR, Rothman JE. 2000. The debate about transport in the Golgi-two sides of the same coin? Cell 102: $713-$ 719.

Penuela S, Bhalla R, Gong XQ, Cowan KN, Celetti SJ, Cowan BJ, Bai D, Shao Q, Laird DW. 2007. Pannexin 1 and pannexin 3 are glycoproteins that exhibit many distinct characteristics from the connexin family of gap junction proteins. J Cell Sci 120: 3772-3783.

Penuela S, Bhalla R, Nag K, Laird DW. 2009. Glycosylation regulates pannexin intermixing and cellular localization. Mol Biol Cell 20: 4313-4323.

Prydz K, Hansen SH, Sandvig K, van Deurs B. 1992. Effects of brefeldin A on endocytosis, transcytosis and transport to the Golgi complex in polarized MDCK cells. J Cell Biol 119: $259-272$.

Puthenveedu MA, Bachert C, Puri S, Lanni F, Linstedt AD. 2006. GM130 and GRASP65-dependent lateral cisternal fusion allows uniform Golgi-enzyme distribution. Nat Cell Biol 8: 238-248.

Qu C, Gardner P, Schrijver I. 2009. The role of the cytoskeleton in the formation of gap junctions by Connexin 30. Exp Cell Res 315: 1683-1692.

Rabouille C, Klumperman J. 2005. Opinion: The maturing role of COPI vesicles in intra-Golgi transport. Nat Rev Mol Cell Biol 6: 812-817. 
A.G. Grieve and C. Rabouille

Ramirez IB, Lowe M. 2009. Golgins and GRASPs: holding the Golgi together. Semin Cell Dev Biol 20: 770779.

Reggiori F, Monastyrska I, Verheije MH, Cali T, Ulasli M, Bianchi S, Bernasconi R, de Haan CA, Molinari M 2010. Coronaviruses Hijack the LC3-I-positive EDEMosomes, ER-derived vesicles exporting short-lived ERAD regulators, for replication. Cell Host Microbe 7: 500508 .

Roth J. 2002. Protein N-glycosylation along the secretory pathway: relationship to organelle topography and function, protein quality control, and cell interactions. Chem Rev 102: 285-303.

Rothman JE. 1994. Mechanisms of intracellular protein transport. Nature 372: 55-63.

Rowe T, Aridor M, McCaffery JM, Plutner H, Nuoffer C, Balch WE. 1996. COPII vesicles derived from mammalian endoplasmic reticulum microsomes recruit COPI. $J$ Cell Biol 135: 895-911.

Rowe T, Dascher C, Bannykh S, Plutner H, Balch WE. 1998. Role of vesicle-associated syntaxin 5 in the assembly of pre-Golgi intermediates. Science 279: 696700.

Saez JC, Berthoud VM, Branes MC, Martinez AD, Beyer EC 2003. Plasma membrane channels formed by connexins: their regulation and functions. Physiol Rev 83: 1359 1400.

Sandvig K, Prydz K, Hansen SH, van Deurs B. 1991. Ricin transport in brefeldin A-treated cells: Correlation between Golgi structure and toxic effect. J Cell Biol 115: 971-981.

Sannerud R, Marie M, Nizak C, Dale HA, Pernet-Gallay K, Perez F, Goud B, Saraste J. 2006. Rab1 defines a novel pathway connecting the pre-Golgi intermediate compartment with the cell periphery. Mol Biol Cell 17: 1514-1526.

Schotman H, Karhinen L, Rabouille C. 2008. dGRASPmediated noncanonical integrin secretion is required for Drosophila epithelial remodeling. Dev Cell 14: 171182.

Schotman H, Karhinen L, Rabouille C. 2009. Integrins mediate their unconventional, mechanical-stress-induced secretion via RhoA and PINCH in Drosophila. J Cell Sci 122: 2662-2672.

Schuldiner M, Metz J, Schmid V, Denic V, Rakwalska M, Schmitt HD, Schwappach B, Weissman JS. 2008. The GET complex mediates insertion of tail-anchored proteins into the ER membrane. Cell 134: 634-645.

Sciaky N, Presley J, Smith C, Zaal KJ, Cole N, Moreira JE, Terasaki M, Siggia E, Lippincott-Schwartz J. 1997. Golgi tubule traffic and the effects of brefeldin A visualized in living cells. J Cell Biol 139: 1137-1155.

Shah D, Shen WC. 1994. The establishment of polarity and enhanced transcytosis of transferrin receptors in enterocyte-like Caco-2 cells. J Drug Target 2: 93-99.

Shitara Y, Kato Y, Sugiyama Y. 1998. Effect of brefeldin A and lysosomotropic reagents on intracellular trafficking of epidermal growth factor and transferrin in Madin-Darby canine kidney epithelial cells. J Control Release 55: $35-43$.
Shorter J, Watson R, Giannakou ME, Clarke M, Warren G, Barr FA. 1999. GRASP55, a second mammalian GRASP protein involved in the stacking of Golgi cisternae in a cell-free system. EMBO J 18: 4949-4960.

Stagg SM, LaPointe P, Razvi A, Gurkan C, Potter CS, Carragher B, Balch WE. 2008. Structural basis for cargo regulation of COPII coat assembly. Cell 134: 474-484.

Stagg SM, Gurkan C, Fowler DM, LaPointe P, Foss TR, Potter CS, Carragher B, Balch WE. 2006. Structure of the Sec13/31 COPII coat cage. Nature 439: 234-238.

Stanley P. 2011. Golgi Glycosylation. Cold Spring Harb Perspect Biol doi: 10.1101/cshperspect.a005199.

Strous GJ, van Kerkhof P, van Meer G, Rijnboutt S, Stoorvogel W. 1993. Differential effects of brefeldin A on transport of secretory and lysosomal proteins. J Biol Chem 268: $2341-2347$.

Sudhof TC, Rothman JE. 2009. Membrane fusion: Grappling with SNARE and SM proteins. Science 323: $474-$ 477.

Tisdale EJ, Bourne JR, Khosravi-Far R, Der CJ, Balch WE. 1992. GTP-binding mutants of rab1 and rab2 are potent inhibitors of vesicular transport from the endoplasmic reticulum to the Golgi complex. J Cell Biol 119: 749-761.

Tsui LC. 1992. Mutations and sequence variations detected in the cystic fibrosis transmembrane conductance regulator (CFTR) gene: A report from the Cystic Fibrosis Genetic Analysis Consortium. Hum Mutat 1: 197-203.

Tveit H, Akslen LK, Fagereng GL, Tranulis MA, Prydz K. 2009. A secretory Golgi bypass route to the apical surface domain of epithelial MDCK cells. Traffic 10: 1685-1695.

van Meer G, van 't Hof W. 1993. Epithelial sphingolipid sorting is insensitive to reorganization of the Golgi by nocodazole, but is abolished by monensin in MDCK cells and by brefeldin A in Caco-2 cells. J Cell Sci 104: 833842.

Vinke FP, Grieve AG, Rabouille C. 2011. The multiple facets of the Golgi reassembly stacking proteins. Biochem J 433: 423-433.

Wagner M, Rajasekaran AK, Hanzel DK, Mayor S, Rodriguez-Boulan E. 1994. Brefeldin A causes structural and functional alterations of the trans-Golgi network of MDCK cells. J Cell Sci 107: 933-943.

Wan J, Taub ME, Shah D, Shen WC. 1992. Brefeldin A enhances receptor-mediated transcytosis of transferrin in filter-grown Madin-Darby canine kidney cells. J Biol Chem 267: 13446-13450.

Wang X, Matteson J, An Y, Moyer B, Yoo JS, Bannykh S, Wilson IA, Riordan JR, Balch WE. 2004. COPII-dependent export of cystic fibrosis transmembrane conductance regulator from the ER uses a di-acidic exit code. J Cell Biol 167: $65-74$.

Wang E, Pennington JG, Goldenring JR, Hunziker W, Dunn KW. 2001. Brefeldin A rapidly disrupts plasma membrane polarity by blocking polar sorting in common endosomes of MDCK cells. J Cell Sci 114: 33093321.

Watson P, Stephens DJ. 2005. ER-to-Golgi transport: form and formation of vesicular and tubular carriers. Biochim Biophys Acta 1744: 304-315. 
Watson P, Townley AK, Koka P, Palmer KJ, Stephens DJ 2006. Sec16 defines endoplasmic reticulum exit sites and is required for secretory cargo export in mammalian cells. Traffic 7: 1678-1687.

Welsh MJ, Smith AE. 1993. Molecular mechanisms of CFTR chloride channel dysfunction in cystic fibrosis. Cell 73: $1251-1254$.

Wieland FT. 2011. COPI Budding within the Golgi stack. Cold Spring Harb Perspect Biol doi:10.1101/cshperspect. a005231.

Wood SA, Park JE, Brown WJ. 1991. Brefeldin A causes a microtubule-mediated fusion of the trans-Golgi network and early endosomes. Cell 67: 591-600.

Xiang Y, Wang Y. 2010. GRASP55 and GRASP65 play complementary and essential roles in Golgi cisternal stacking. J Cell Biol 188: 237-251.
Xu H, Boulianne GL, Trimble WS. 2002a. Drosophila syntaxin 16 is a Q-SNARE implicated in Golgi dynamics. J Cell Sci 115: 4447-4455.

Xu Y, Martin S, James DE, Hong W. 2002b. GS15 forms a SNARE complex with syntaxin 5, GS28, and Ykt6 and is implicated in traffic in the early cisternae of the Golgi apparatus. Mol Biol Cell 13: 3493-3507.

Yoo JS, Moyer BD, Bannykh S, Yoo HM, Riordan JR, Balch WE. 2002. Non-conventional trafficking of the cystic fibrosis transmembrane conductance regulator through the early secretory pathway. J Biol Chem 277: 11401-11409.

Zuber C, Cormier JH, Guhl B, Santimaria R, Hebert DN, Roth J. 2007. EDEM1 reveals a quality control vesicular transport pathway out of the endoplasmic reticulum not involving the COPII exit sites. Proc Natl Acad Sci 104: $4407-4412$. 


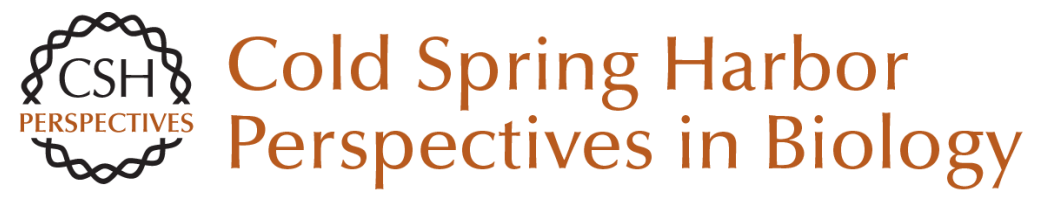

\section{Golgi Bypass: Skirting Around the Heart of Classical Secretion}

Adam G. Grieve and Catherine Rabouille

Cold Spring Harb Perspect Biol 2011; doi: 10.1101/cshperspect.a005298 originally published online March 16, 2011

\section{Subject Collection The Golgi}

Structure of Golgi Transport Proteins

Daniel Kümmel and Karin M. Reinisch

\section{Golgi Biogenesis}

Yanzhuang Wang and Joachim Seemann

Golgi Glycosylation and Human Inherited

Diseases

Hudson H. Freeze and Bobby G. Ng

Models for Golgi Traffic: A Critical Assessment

Benjamin S. Glick and Alberto Luini

Architecture of the Mammalian Golgi Judith Klumperman

Evolution and Diversity of the Golgi Mary J. Klute, Paul Melançon and Joel B. Dacks

Evolutionary Forces Shaping the Golgi

Glycosylation Machinery: Why Cell Surface

Glycans Are Universal to Living Cells Ajit Varki

Golgi Positioning

Smita Yadav and Adam D. Linstedt
Golgi and Related Vesicle Proteomics: Simplify to Identify Joan Gannon, John J.M. Bergeron and Tommy Nilsson

Organization of SNAREs within the Golgi Stack Jörg Malsam and Thomas H. Söllner

Golgi during Development Weimin Zhong

Entry and Exit Mechanisms at the cis-Face of the Golgi Complex Andrés Lorente-Rodríguez and Charles Barlowe

COPI Budding within the Golgi Stack Vincent Popoff, Frank Adolf, Britta Brügger, et al.

Mechanisms of Protein Retention in the Golgi David K. Banfield

The Golgin Coiled-Coil Proteins of the Golgi

Apparatus Sean Munro

Signaling at the Golgi Peter Mayinger

For additional articles in this collection, see http://cshperspectives.cshlp.org/cgi/collection/

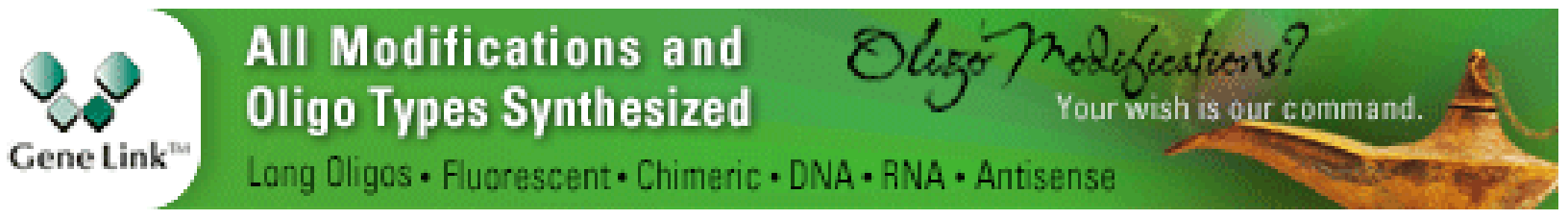

Copyright @ 2011 Cold Spring Harbor Laboratory Press; all rights reserved 